\title{
El Terremoto en la Literatura Peruana
}

L 24 de mayo del año de 1940, Lima se vió conmovida por un terremoto, que violentamente nos puso en contacto con su reconocida fama de ciudad de temblores. Una gran parte de la zona antigua y muchos lugares tradicionales, sufrieron irreparables consecuencias. Los limeños se sintieron un poco ofendidos por esta manifestación de la naturaleza, que interrumpía en forma tan inesperada la dulce modorra de su eterna primavera. $\mathrm{Y}$ entonces, entre las conversaciones, un poco para alejar el miedo y otro poco para olvidarse del dolor, surgieron los recuerdos de anteriores movimientos sísmicos, que desde la colonia dejaron una huella pavorosa o anecdótica. Con este motivo me puse yo a hurgar entre papeles viejos, donde encontré graves y abundantes testimonios sobre la forma de asustarse de los limeños en estas ocasiones. Los resultados no dejan de ser interesantes, y por eso los vertí en una conferencia cuya versión, asísmica e inconmovible, doy en estas páginas, que sólo se reclaman del mérito de todos los que escribieron en el Perú, sobre la peripecia constante e irrenunciable de sus terremotos.

Tenemos que hablar de los tiempos en que Lima surgía enamorando a los viajeros que llegaban a su valle exquisitamente templado, y se adormecían en la gama de suaves colores de su campiña. Pero de pronto, cuando más confiados estaban, la naturaleza les hacía sentir el imperio de su fuerza. En esos momentos todos los habitantes se acordaban de Dios momentáneamente, la voz de los sacerdotes resonaba con ecos de admonición desde los púlpitos de las iglesias magníficas $y$, en las conversaciones pueblerinas, se contaban los hechos maravillosos en los que la voluntad divina se había puesto en evidencia. Este es el tono de nuestras primeras Relaciones, al mismo 
tiempo de perfil trascendente y de primitiva ingenuidad, pero donde el terror dejaba una marca indeleble y profundamente humana.

Un afán apostólico y ejemplarizador convertía en muy sabrosas algunas de estas Relaciones. Nos es fácil comprobarlo, recorriendo una página de fray Antonio de la Calancha, que en el Libro II de su Crónica moralizada, justifica su título al referirnos un suceso ocurrido durante el terremoto de Trujillo, de muy profundas conclusiones morales:

En el oficio de un escribano estavan aziendo una escritura dos; y el ano engañava y el otro sufría: aquel vendía la necesidad. y estotro callava su agravio. El escribano favorecía la causa del mal echor. $\mathrm{y}$ todos los mas testigos $\mathrm{y}$ asistentes eran paniaguados $\mathrm{y}$ cooperates en la maldad; ya se iva acabando la escritura para firmar el contrato, comenzó el temblor, y dijo el agraviado, huyamos que tiembla; y respondió el agraviador, luego pasará, acabemos esto. Continuava el furor cayendo terrones, quiso huir el inocente, detúvole el maliciosó, diciendo: no sea tan cobarde, que ya pasa. Viendo el escribano que iva arreziando el furor quiso saltar la mesa que les atajava el paso, $y$ detúvole el interesado, con que pudo el inocente, y otro su amigo, salir a la plaza, y cayendo todo el edificio le cogió un madero la cabeza entre el canto de la mesa donde escrivía y las manos con que estava escribiendo, y se las cortó como pudiera una navaja. ${ }^{1}$

Este relato es verdaderamente conmovedor, pero no es único. La lectura de otros Cronistas, como por ejemplo, fray Bernardo de Torres en el Tomo $4^{\circ}$ de su Crónica de la Provincia Pernana de los Ermitaños de San Agustín, nos permite llegar a reflexiones inesperadas, acerca del valor de hombres y mujeres ante el peligro:

A trece de Noviembre de 1655 -dice el agustino- a las dos y tres cuartos de la tarde en oposición de Lima fatigó a esta ciudad de los Reyes Corte del Perú, uno de los más terribles y executivos temblores que hasta hoy se han visto en este reino. Con dificultad se podrá discernir qual efecto fué más formidable, si el movimiento y el espanto de los baybenes con que sacudió la tierra, los montes y los edificios de la ciudad, y de quantos pueblos se contiene en cien leguas de costa Norte Sur, y cincuenta Este Oeste: o los clamores, lágrimas $y$ raras penitencias, que los afligidos y temerosos limanos hizieron publicamente para detener el brazo ayrado de la justicia divina. $Y$ menos se puede juzgar, quiénes se mostraron más varoniles en esta ocasión, si las frágiles mujeres o los robustos hombres. 2 
En esta última frase, fray Bernardo estuvo verdaderamente fustigante. Junto a él, fray Meléndez no puede ocultar su simpatía por Lima, aun cuando trate de temas tan áridos como los del terremoto:

$\mathrm{Ha}$ padecido Lima - dice el Cronista- en diversos tiempos los amagos de su ruina con horribles tertemotos, impidiendo su heredado temor la altura de sus casas, y no dejando tejar sus edificios, que si se asegurara del todo y levantara sus azoteas, fuera sin contradicción la ciudad más hermosa que ilustrara el mundo. 3

Así fray Juan pone sobre la gracia limeña un elogio encendido e hiperbólico. Después, en su misma Crónica, relatará el terremoto de Lima, del 17 de junio de 1678. Pero la Ciudad de los Reyes ya había pasado, antes, por duras pruebas.

Una de ellas es el terremoto de 1582. Un poeta, Martín del Barco Centenera, nos da una minuciosa descripción de él, en su libro Argentina y conquista del Río de la Plata. Sus palabras son pintorescas y llenas de franqueza al relatarnos muchas escenas:

$Y$ no se quedó Lima sin su suerte De pena en este tiempo semejante Que un terremoto grande, crudo y fuerte Sucede una mañana en un instante, No ay hombre que a salir de casa acierte $\mathrm{Y}$ aquel que corre más sale delante No espera la mujer a su marido La madre dexa al hijo muy querido.

De ver era mirar como salían

Con mil disfraces hombres y las damas

Las unas en camisa desgreñadas Las otras dando gritos mal cubiertas Las otras medias caras afeytadas Caydas, desmayadas a las puertas, Las otras con sus hijos abrazadas, Vencidas del temor y medio muertas. Al fín pasó el tempblor aunque turbada Quedó la gente toda y espantada. 4 
En cuanto a la importancia del temblor de 1609, ha quedado en la inmortalidad, gracias al Poema de Pedro de Oña que, aunque chileno de nacimiento, tiene para nosotros esta temblorosa vinculación sísmica. El año de 1909, el erudito J. Toribio Medina reimprimió en Santiago "El Temblor de Lima de 1609 por el Licenciado Pedro de Oña". Uno de los méritos de esta composición es -según lo hace notar el propio Medina- que a pesar de trabajar con mucha lentitud las prensas en esa época, el poema que refería el terremoto del 19 de octubre vió la luz el mismo año. Esto revela una inspiración relómpago en la creación del autor. Oña tenía gran apego a Lima, entre otras razones, porque había estado matriculado en el primer curso de Artes de nuestra Universidad de San Marcos.

Para organizar la trama del poema, el autor planea una ficción por la cual dos amigos, Arcelo y Darío, que caminaban una tarde de invierno por la sierra peruana, se vieron sorprendidos por una tempestad y tuvieron que refugiarse en una cueva. Allí Arcelo, a petición de Darío, refiere el acontecimiento ocurrido en Lima:

Al tiempo que la noche desplegaba

Su triste sombra desterrando al día

Cuando con más cuidado Lima estaba

Cierta señal del daño que venía

A la sazón que en casa el hombre entraba

$\mathrm{Y}$ que de casa la mujer salía,

Aquel para mudar el traje honesto

$Y$ esta para buscar lo que no es esto.

Cual su alma juzgando y cual haciendo

Hora (que ha de costarle eternos años)

$Y$ cual estaba ante una cruz gimiendo

Tanta ofensa de Dios, y tantos daños;

Cuando se empieza un repentino estruendo

$Y$ con vaivenes a moverse extraños

La firme tierra y cuanto carga encima

Como resulta de arrasar a Lima.

Como se puede apreciar, estos versos tienen la confusión propia de los terremotos. Pero páginas más adelante manifiesta, en cambio, una lograda visión de poeta, cuando habla de la cólera divina:

Ay hombre, no eres hombre, antes encina

Si cuando mal te tratan das el fruto, 
El bruto, a quien le trata bien, se inclina

Ven, hombre, ven; aprenderás del bruto.

Mas Oh bondad sin límite, divina

Que aunque por fuerza, y de ánimo corruto

Lo que ella da, recibes tú de agrado

Queriendo hacer del muladar, sagrado. 5

Pero el limeño es de un carácter despreocupado, y pronto olvida los momentos trágicos. De tiempo en tiempo, violentas advertencias ponen su terror cósmico en el paisaje, y la alegría gozosa es olvidada, para dejar el paso a una meditación. Los diarios de Lima, de Suardo y Mugaburu, lo atestiguan así. Como es sabido, el primero abarca desde 1629 a 1634. Toma su función con toda seriedad, y consigna los hechos más domésticos que pueden ocurrir en la naciente población, junto a los de auténtica trascendencia. Suardo fué testigo del gran temblor habido el 27 de noviembre de 1630, y lo describe en esta forma :

Este día, a las once y media del dia en punto, huvo en esta ciudad un temblor de los más grandes que ha avido, desde cinquenta años a esta parte, que duró mas de un miserere y medio y si, como vino por alto huviera venido por baxo de la tierra, es sin duda que quedava asolada toda esta república.

Lo del "miserere y medio" indica su importancia; y el mismo Suardo la confirma, más adelante, calculando "en más de un millón el daño"'.6

Josephe de Muigaburu, en su Diario de Lima, no se queda atrás. Habla de los terremotos de Pisco e Ica, de Huancavelica, del temblor de Lima de 1678 y, por último, del que se produjo en 1687, que le suscita muy filosóficos comentarios:

Martes $1^{\circ}$ de Abril de 87 años, postrero día de Pascua de Resurrección, a las once y tres cuartos de la noche, hubo un temblor tan horrible por la furia con que empezó, como no comparable con la fuerza con que estremeció toda la ciudad. $Y$ más de un mes antes se andaba divulgando que por una revelación se sabía esto: Dios nos mire con ojos de piedad, que semejante cosa no se ha oido; y se conoció en el modo de remecer que era azote de la mano de Dios. 7

Si nosotros queremos amenizar la adustez de estos Diarios y Crónicas, con la alada inspiración de nuestros genios poéticos, pode- 
mos recurrir al muy docto Pedro Peralta Barnuevo Rocha Benavides. Oigamos cómo, en su Lima fundada, habla de toda clase de terremotos, entre ellos, del acaecido en Chile:
Subtertáneos furores que encendidos
Planteles son sulphureos de volcanes
$Y$ exhalados a un tiempo y recogidos
Son los rayos del orbe y los titanes
Valles y montes de golpe heridos
Mezclando las alturas con los planes
Serán en Chile tan violentas minas
Que apenas quede suelo a las rüinas.

Estas sulphureas rimas se prolongan en muchos versos que tratan de los terremotos de Lima de 1630, 1678 y 1687, el último de los cuales tiene una explicación científico-poética de altos quilates:

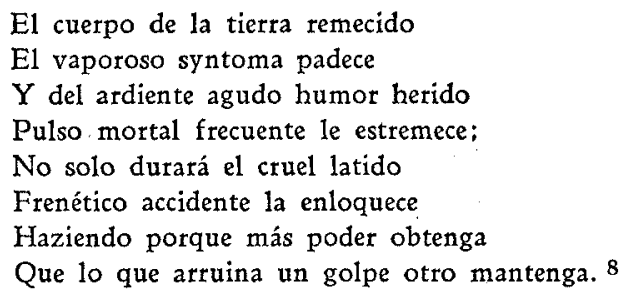

Haciendo contraste con Peralta, aparece el espíritu socarrón de Juan del Valle Caviedes, verdadero criollo, aunque hubiera nacido en tierras españolas. E1 es un doble sobreviviente de los médicos y del terremoto. $\mathrm{Y}$ aun en medio del pánico, escribe una décima protestando de la costumbre adquirida por un médico que, a consecuencié del terremoto, empezó a usar espada:

Tembló la tierra preñada

$Y$ al punto que se movieron

Los montes, luego parieron

A liseras con espada.

Porque su traza jibada

Sin forma ni perfección

Como es globo en embrión

Hecho quirúrgica bola

Así que se puso cola

Quedó físico ratón. ${ }^{9}$ 
También son suyas aquellas estrofas en que se pregunta:

\author{
Qué hicieron Lima ilustre \\ tus fuertes arquitecturas \\ de templos, casas y torres \\ como la fama divulga? \\ . \\ No quedó templo que al suelo \\ no bajase, ni escultura \\ sagrada de quien no fueran \\ los techos violentas urnas...
}

(Don Esteban Terralla y Concolorcorvo fueron significativos viajeros que llegaron a Lima por dos distintas sendas. El malhumorado andaluz viene del Norte lejano de México y escribe lo que se podría calificar de un magnífico planfleto poético contra Lima. El sagaz y astuto Bustamante, describe el viaje realizado desde el extremo Sur del continente por la ruta del Alto Perú. Verdaderamente admira que ni Terralla en su Lima por dentro y por fuera, ni Concolorcorvo en El lazarillo de ciegos caminantes se hubieran interesado por el permanente problema limeño de los terremotos. Misteriosos designios sobrenaturales lo impidieron, y hay que rendir tributo a este paréntesis de discreción.)

Pero este vacío lo llena el muy ilustre Rodrigo de Carbajal y Robles, que en su libro sobre las Fiestas que celebró la Ciudad de los Reyes al nacimiento del Serenisimo Príncipe don Baltasar Carlos de Austria, describe la interrupción de la alegría ciudadana ócasionada por el temblor:

Sobresaltó la fiesta un alboroto que sacudió $\tan$ fiero un terremoto del aire, que se encierra en las concavidades de la tierra

Viéronse estremecer fornidas rocas y abrir la tierra formidables bocas, rajarse peñas, desgastarse riscos, hervir la arena, trastornarse el suelo. crujir los encumbrados obeliscos. ensordecerse el cielo, bramar el duro monte, 
cegarse el horizonte, con las nubes de polvo que se hacían del que los edificios sacudían. 10

La descripción no puede ser más patética; pero aunque parezca mentira, el Conde de la Granja lo supera en dramatismo, cuando en su Vida de Santa Rosa describe un terremoto en Quito:

Los Polos en sus basas vacilaton

A1 violento bayben del terremoto

La fábrica celeste desplomaton

Un eje y otro de sus quicios roto:

Los astros entre si se barajaron

Aun los que tienen el engaste inmoto

Quedando al contratiempo que le altera

Descoyuntado el cuerpo de la esfera. ${ }^{11}$

Más literario, Juan de Miramontes, en sus Armas antárticas, alude a uno de nuestros temblores, en su Canto virr:

Pues ves que los profundos se estremecen

Asperos infortunios anunciando

A tiempo que en los cielos se parecen

Prodigios, cierta guerra amenazando:

Los vientos de turbiones se oscurecen

$Y$ las concavidades retumbando

Publican que principios son expresos

De escandalosos males y sucesos. 12

La musical inspiración de los poetas se ve, en algunas ocasiones, interrumpida por las atropelladas explicaciones de los escritores en prosa. Si hojeamos el volumen de la colección Odriozola, dedicado a los terremotos, encontramos esta peligrosa narración motivada por el sismo de 1687 :

La Ciudad de Lima, que es la patria de la abundancia y riqueza, como puede reconocerse en los tesoros que en esta armada del año de 1690, remite a España ... padece dentro desí su mayor trabajo, pues formándose en los senos y cabernas de la tierra sulfúreas tempestades, rompen a veces con tan escandaloso estremecimiento, que nos dan a padecer los sustos de las postreras ruinas. Este mal, entre todos es más general e inevitable, como disputa Séneca en sus cuestiones naturales; porque ¿dónde hallará refugio un combatido, cuando es 
igual en todas partes la amenaza? ¿Qué escape puede haber, donde el miedo aprisionado no puede huir? ¿Qué lugar hay defendido que pueda ser de otros y de si mismo defensa? ${ }^{13}$

A estas filosóficas descripciones hay que añadir la del padre Joseph Buendía; ${ }^{14}$ la de Francisco Antonio de Montalvo que dice: "Todo de aquella tierra desunido y arrebatado de su centro horrendamente confuso tembló..."; ${ }^{15}$ la del padre Castillo en stu Autobiografía, ${ }^{16}$ y otras que cansaría oírlas enumerar: Memorias de los Virreyes, Historia del Nuevo Mundo por el padre Bernabé Cobo, etc., etc.

En el siglo xvirI, los prosistas tienen verdadero predominio. Varios extranjeros se abisman ante este fenómeno inusitado. E1 padre Niel hace un elogio de Lima y una lamentación de sus terremotos, ${ }^{17}$ y Jorge Juan y Antonio de Ulloa los sitúan dentro de una clasificación muy curiosa. Los conocidos viajeros, en su Relación histórica del viaje a la América Meridional, después de hablar de las plagas de Lima en verano (las chinches y las pulgas), dicen: "A las plagas de los insectos sigue el riezgo de los terremotos; siendo tal la propensión de aquel país a ellos, que sus habitadores viven con el continuo sobresalto de sus estragos." Anotan, también, que los ruidos que los preceden son como mugidos de buey y tiros de artillería. ${ }^{18}$ Pero esta descripción y la Epístola que escribió el Marqués de Obando sobre la inundación del Callao y terremoto de 1746, palidecen ante los términos de la Carta que Eusebio Zapata y Llano escribió a su venerado amigo el doctor Ignacio Chiriboga y Daza, canónigo de la Santa Iglesia de Quito, en la cual manifiesta una erudición que sobrecoge :

"Afirma Aristóteles que los más temblores acontecen de noche: Esto mismo San Alberto Magno, y el padre Juan Zapata Kinter que en serenidad de Cielo, tranquilidad de Mar y, quietud de la Tierra, suceden sus más grandes movimientos, como lo experimentó Lima en la mencionada noche y se verá abajo el efecto de su estrago." $Y$ luego, añade:

A las diez de la noche en este día abortaron las nubes una especie de menuda lluvia que continuó cayendo hasta las siete de la mañana del siguiente día, y creo que abiertas las oficinas subterráneas, y rotos los conductos y poros, con los repetidos movimientos saldrian ejércitos de exhalaciones mezcladas de las partículas nitrosas sulfúricas y oleaginosas, que volviendo a buscar el centro de la tierra, conver- 
tidos ya en malignas gotas por infrigidación del aire superior, esterilizaron los campos y abrazaron las sementeras dejando a los hombres con la malignidad de su respiración y pestíferos eruptos de sus bostezos, expuestos a catarros, dolotes pleuríticos y profluvios de vientre. 19

Hay narradores patéticos, que toman las cosas por el lado sentimental. Uno de ellos es J. A. Reynolds, que con motivo del movimiento del año 1746, estampa estas líneas:

Por aquí se veía al padre preguntar por el hijo; al hijo llorar la pérdida de la madre; más allá al pariente lamentar sus relacionados y amigos. Todo era consternación y dolor. Los hombres hablaban sin tino, pero sus pensamientos se leían en sus miradas. La magnitud de su pesar la manifestaban con la vista convulsiva. En fin, no era una vida la que lloraban sino una muerte lenta la que sufrían ...20

No podía faltar el tema del terremoto entre las Tradiciones peruanas. Un rápido recorrido nos informa de variadas alusiones; pero singularmente en el tomo II, anotamos una Tradición titulada "Conversión de un libertino", cuyo eje central es el movimiento sísmico de 1746. En ella Ricardo Palma recoge la copla popular que se cantaba entonces:

Un faldellin he de hacerme

de bayeta de temblor

con un letrero que diga

iMisericordia Señor!

Cuenta nuestro tradicionista la historia de don Juan de Andueza, mozo alegrón y enamoradizo que se encontraba en una jarana, donde se cantaba aquello de:

\author{
Levántamelo María \\ levántamelo José \\ si tú no me lo levantas \\ yo me lo levantaré. \\ Que se quema el sango \\ ¿No se quemará! \\ Pues vendrán las olas \\ y lo apagarán.
}


Para castigarlos, el mar quiso apagar el sango. ${ }^{21}$

Clemente Althaus, también perteneciente a nuestra generación romántica, dedica uno de los sonetos incluidos en sus Obras poéticas a describir el temblor. He aqui la primera estrofa:

\footnotetext{
Temblor, temblor: con subterráneo ruido

Velocísino llega de repente;

Moverse el suelo, cual bajel, se siente

Y crujir techo y muro sacudido . . 22
}

Y Manuel Atanasio Fuentes, el inimitable "Murciélago", determina en las páginas de su popular libro sobre Lima, las épocas en que se producen los temblores. Sus afirmaciones están construídas en tal forma, que no corre peligro de equivocarse, cuando dice, textualniente, que: "La estación en que más se repite este fenómeno es entre la primavera y el estío, aunque no sea muy extraño en el otioño." Para completar su observación tan precisa, sólo le faltó decir que, en algunos casos, también se producían los temblores en invierno. Luego añade que "el número medio de los temblores, al año, es de ocho". ${ }^{23}$

Así llegamos hasta la poesía de José Santos Chocano, toda recorrida de temblores cósmicos, como cuando en su fragmento de epopeya El Hombre Sol, describe el despertarse de las cumbres:

\footnotetext{
Y como recortidas por un temblor, de pronto

las cumbres de los Andes se despiertan . . . 24
}

Nuestra generación modernista no sintió tan próximo el problema del terremoto. Las frases agudas que sugería cualquier temblor se perdían en las conversaciones gratas y matizadas a que eran tan afectos los poetas. Sin embargo, queda la inspiración de uno de sus mejores representantes, José Gálvez, quien en su canto jubitar "A Lima”, recuerda:

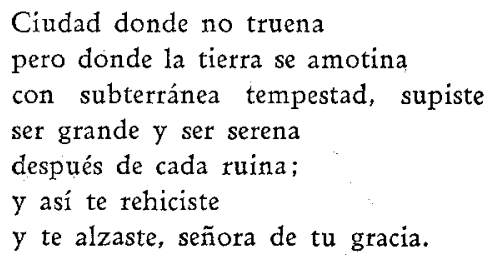


En cambio, para los de la Generación del 18 el terremoto significó otro centro de interés: aparece la etapa de interpretación. Jorge Basadre escribe, en uno de sus libros, que en el decurso de nuestra formación "el terremoto balanceaba la obra sedante y disolvente del clima, de la vida regalada". ${ }^{25}$ Corrobora esta opinión una página de Jorge Guillermo Leguia, quien al hablar de Lima en el siglo XVIII dice: "Frecuentemente era un terremoto, un temblor intenso, una peste o la sequía y esterilidad de los campos, la chispa que encendía en aquel sentido el alma de nuestra sociedad." ${ }^{26}$ Algunos años más tarde, Raúl Porras, en su Perspectiva y panorama de Lima, hace notar que la garia y los temblores constituyen elementos indispensables para comprender a Lima: "Ambos definen momentos de la ciudad y deciden matices sicológicos del alma limeña." 27 Junto a ellos, Héctor Velarde sutiliza gravemente sobre sus diversos aspectos, en tantas páginas que no es necesario citar por ser demasiado conocidas, impregnadas del ingenio de su espíritu sagaz.

En esta forma llegamos a nuestra experiencia más próxima. Ya sobre ella Torres de Vidaurre ha escrito un romance con reminiscencias lorquianas. $Y$ los sismógrafos, empeñados en dejar malparadas las estadísticas de Manuel A. Fuentes, se esfuerzan en registrar temblores en todas las estaciones del año, y en un número que supera en varias decenas a los cálculos más pesimistas de nuestro inquieto limeñista.

\section{Luis Fabio Xammar, Lima, Perú.}

\section{B I B L I O GRAF I A}

1 Crónical motalizada/ del otden de/ San Agustín en el/ Perú, con sucesos/ ejemplates en esta/ Monatquía, etc., etc., por Fray Antonio de la Calancha. Lima, 1638. (Libro II, Cap. XXXVI.)

2 Crónical de la provincial peruana del orden de los/ ermitaños de San Agustín/ nuestto padre:/ dividida en ocho libros/ etc., etc., por Fray Bernardo de Torres. Lima, 1657. (Libro $4^{\circ}$, Capítulo XXII.)

3 Tesoros/ verdaderos/ de las Indias/ en la historia de la gran provincial etc., etc., por Fray Juan Meléndez. Roma, 1681. (Libro II, Capítulo I.) 
4 Argentinal y conquista del Ríol de la Plata, con otros acae-/ cimientos de los Reynos del Perú. Tucumán y esta-l do del Brasil, por el Arcediano don Martín del/ Barco Centeneral etc. etc. Lisboa, 1602. (Canto XXIII.)

5 Temblor del Lima años de 1609/ Gobetnando el Marqués/ de Montesclatos, Vitrey Excellentísimol y una canción teal panegitica en lal venida de su Excellencia al etc., etc., por el Licenciado Pedro de Oña. Lima, 1609.

6 Diario de Lima de Juan Antonio Suardo (1629-1634).

7 Diario de Lima de Joseph Mugaburu (1640-1694).

8 Lima Fundadal o conquista del Perúl poema hetoicol en que se decanta toda la Historial del descubrimiento y sugeción de sus provincias/ por Don Ftancisco Pizarto, Marqués del los Atabillos, Inclito y Primet Gobernador del etc., etc., por Don Pedro Peralta Barnuevo. Lima, 1732. (Canto VI.)

9 Juan del Valle Caviedes, Diente del Parnaso.

10 Biblioteca de Cultura Peruana, El apogeo de la literatura colonial.

11 Vidal de Sta. Rosal del Santa Matial natural de Limal y patrona del Perúl poema heroyco/ por don Luis Antonio de Oviedol y Hertera, caballeto del orden de Santiago/ Conde de la Granja. Madrid, 1711. (Canto VI.)

12 Juan de Miramontes Zuázola, Atmas antátticas. (Canto VIII.)

13 Tetremotos/ colección de las Relaciones/ de los más notables que ha sufridol esta capital/ y que la han artuinado/ etc., etc., colectadas y arregladas por el Coronel de Caballería de Ejército Don Manuel de Odriozola. Lima, 1863. (pág. 23.)

14 Vida admitablel y prodigiosas vittudes/ del venerable y apostólico/ padrel Francisco del Castillo/ de la Compañía de Jesús/ etc., etc., por el padre Joseph de Buendía. Año MDCXCIII. (pág. 637.)

15 El soll del nuevo mundol ideado y compuestol en las esclarecidas operaciones/ del Bienaventuradol Toribiol Arzobispo de Limal por el doctor Don Francisco Antonio de Montalvo. Roma, 1683. (pág. 22.)

16 Autobiografía del padre Castillo. Rev. del Archivo Nacional. (Tomo III.)

17 Cattas/ edificantes y curiosas/ escritas/ de las misiones/ extrangeras/ por/ algunos misionetos/ de la compañia de Jesús/ etc., etc. Madrid, 1754. (Tomo III, pág. 266.)

18 Relación histórical del viajel a la América Meridionall hechol por orden de su Magestadl para medir algunos grados de metidianol etc., etc., por Don Jorge Juan y Don Ántonio de Ulloa. Lima, 1748. (Libro I, Parte II, Capítulo VII.) 
19 Manuel Odriozola, Colección de documentos literarios del Perú.

20 Historia de la ruina de Lima y del Callao en el año de 1746, traducida de las obras de Don J. A. Reynolds. Lima, 1860. (Segunda edición.)

21 Ricardo Palma, Ttadiciones peruanas. (Tomo II, pág. 157.)

22 Clemente Althaus, Obras poéticas. Lima, 1872.

23 Manuel A. Fuentes, Lima. París, 1867. (pág. 5.)

24 José Santos Chocano, Ayacucho y los Andes. Lima, 1924. (Canto IV, I.)

25 Jorge Basadre, La multitud, la ciudad y el campo en la Historia del Perú. Lima, 1929. (pág. 80.)

26 Jorge Guillermo Leguía, Lima en el siglo XVIII. Lima, 1921. (pág. 21.)

27 Raúl Porras, Pequeña antología de Lima. Madrid, 1935. (pág. 18.) 